\title{
ILLNESS REPRESENTATION PADA PASIEN DENGAN HIPERTENSI
}

\author{
Illness Representation In Patients With Hypertension \\ Andri Setyorini*, Niken Setyaningrum \\ STIKes Surya Global Yogyakarta \\ (andrisetyo04@gmail.com/Hp. 085228459408)
}

\begin{abstract}
ABSTRAK
Penyakit tidak menular yang menyebabkan kematian tertinggi di dunia salah satunya adalah penyakit hipertensi. Tatalaksana hipertensi dapat dilakukan dalam dua kategori yaitu non farmakologi dan secara farmakologis. Namun Pada pelaksanaannya tentu dapat menimbulkan kejenuhan dan stres karena mereka harus menaati program diet yang dianjurkan selama hidupnya. Tujuan penelitian ini adalah untuk mengetahui gambaran terkait "Illness Representation pada Pasien dengan Hipertensi. Penelitian ini menggunakan pendekatan diskriptif kualitatif dengan pengumpulan data menggunakan wawancara mendalam (in depth interview), observasi berperan (participant observation) dan dokumentasi. Analisis data menggunakan qualitative content analysis (analisis isi). Penelitian ini menghasilkan 6 tema berdasarkan tujuan penelitian yaitu : 1) pemahaman dari penyakit hipertensi, 2) keluhan yang dirasakan, 3) penyebab penyakit, 4)lama penyakit berlangsung, 5) komplikasi yang mungkin muncul, dan 6) Kontrol atau pengobatan. Kesimpulan dari hasil penelitian ini adalah bahwa gambaran terkait Illness Representation pada Pasien dengan Hipertensi terkait dengan pemahaman penyakit, keluhan yang dirasakan, penyebab penyakit, lama penyakit berlangsung, komplikasi yang mungkin muncul, dan Kontrol atau pengobatan.
\end{abstract}

Kata kunci: Illness Representation, Hipertensi

\begin{abstract}
Non-communicable diseases that cause the highest death in the world, one of which is hypertension. Management of hypertension can be done in two categories, namely nonpharmacological and pharmacological. But in practice it can certainly cause boredom and stress because they have to obey the recommended diet program during his life. The purpose of this study is to determine the picture related to "Illness Representation in Patients with Hypertension. This study uses a qualitative descriptive approach to data collection using indepth interviews, participant observation and documentation. Analysis of data using qualitative content analysis. This study produced 6 themes based on the research objectives, there are: 1) understanding of hypertension, 2) perceived complaints, 3) causes of disease, 4) duration of illness, 5) complications that may arise, and 6) Control or treatment. The conclusion from the results of this study is that the picture related to Illness Representation in Patients with Hypertension is related to understanding the disease, perceived complaints, causes of the disease, duration of illness, complications that may arise, and control or treatment.
\end{abstract}

Keywords: Illness Representation, Hypertension 


\section{PENDAHULUAN}

Penyakit tidak menular saat ini menjadi perhatian yang sangat penting pada sektor kesehatan masyarakat, karena memiliki predikat sebagai penyebab tingginya angka kesakitan dan kematian. Salah satu penyakit tidak menular yang menyebabkan kematian tertinggi di dunia adalah penyakit kardiovaskuler, dimana tingginya angka mortalitas pada penyakit kardiovaskuler tersebut disebabkan oleh faktor risiko utama, yaitu peningkatan tekanan darah (hipertensi). Peningkatan tekanan darah seseorang akan meningkatkan risiko terkena stroke dan penyakit jantung coroner (WHO, 2011). Menurut data WHO, di seluruh dunia sekitar 972 juta orang atau $26,4 \%$ orang di seluruh dunia mengidap hipertensi, angka ini kemungkinan akan meningkat menjadi 29,2\% di tahun 2025. Dari 972 juta pengidap hipertensi, 333 juta berada di negara maju dan 639 sisanya berada di negara berkembang, termasuk Indonesia.

Prevalensi hipertensi secara nasional dalam hasil Riset Kesehatan Dasar (Riskesdas) tahun 2013 berdasarkan hasil pengukuran tekanan darah oleh tenaga medis mencapai $25,8 \%$ dan 3 provinsi yang memiliki prevalensi hipertensi tertinggi berdasarkan diagnosis tenaga kesehatan adalah provinsi Sulawesi Utara $(15,0 \%)$, Kalimantan Selatan (13,1\%) serta DI Yogyakarta $\quad(12,8 \%)$
Kesehatan RI, 2013; Yonata, Satria and Pratama, 2016).

Tatalaksana hipertensi dapat dilakukan dalam dua kategori yaitu non farmakologi dan secara farmakologis. Namun Pada pelaksanaannya tentu dapat menimbulkan kejenuhan dan stres karena mereka harus menaati program diet yang dianjurkan selama hidupnya.

Pemahaman pasien tentang penyakit dapat dilihat dalam konstruk representasi penyakit terdiri dari dimensi identitas, faktor penyebab, periode, dampak, dan tingkat kesembuhan penyakit. Masing-masing dimensi akan bertindak sebagai stressor yang harus dihadapi oleh pasien dengan menggunakan strategi pengatasan tertentu, seperti: ekspresi emosional, dukungan sosial, restrukturisasi kognitif, perilaku penghindaran, modifikasi stressor, dukungan spiritual, dan daya tahan (Fitri and Fensi, 2008).

Sakit dimaknai sebagai suatu kondisi fisik dan psikis, individu merespon gejala penyakit yang muncul secara berbeda, dan pemaknaan sakit dapat berubah sesuai dengan situasi yang dihadapi oleh penderita(Hamzah, Dewi and Suparno, 2014).

\section{METODE}

Penelitian ini menggunakan pendekatan diskriptif kualitatif yang dilakukan pada 
natural setting (kondisi alamiah). Sumber data primer dan tehnik pengumpulan data lebih banyak pada wawancara mendalam (in depth interview), observasi berperan (participant observation) dan dokumentasi. (Sandelowski, 2000; Creswell John W, 2014). Partisipan pada penelitian ini diseleksi sebelumnya dengan menggunakan tehnik purposive sampling. Partisipan pada penelitian ini adalah pasien hipertensi yang menjalani rawat jalan di Puskesmas Panggang II kabupaten Gunungkidul dan belum terjadi komplikasi kronik berjumlah 7 orang.

\section{ANALISIS DATA}

Penelitian ini menggunakan qualitative content analysis (analisis isi) untuk menginterpretasikan diskripsi data yang didapat dari seluruh wawancara yang dilakukan pada partisipan terkait Illness Representation pada Pasien dengan Hipertensi (Sandelowski, 2000; Nursalam, 2015)

\section{HASIL}

Gambaran reperesentasi penyakit (Illness Represetations) pada pasien hipertensi merupakan gambaran dari sakit yang diderita oleh pasien hipertensi tersebut dan berdasarkan wawancara mendalam yang telah dilakukan pada 7 partispan maka ada beberapa tema yang muncul terkait Illness
Represetations pada pasien dengan hipertensi tema tersebut terkait tentang pemahaman penyakit hipertensi, keluhan yang dirasakan, penyebab penyakit, lama penyakit berlangsung, komplikasi yang mungkin muncul, dan kontrol/pengobatan pada penyakit tersebut.

\section{Pemahaman Penyakit Hipertensi (Identity)}

Berdasarkan hasil wawancara mendalam yang telah dilakukan kepada 7 partisipan diperoleh data bahwa ada 1 partisipan yang mengatakan bahwa hipertensi adalah sakit yang berat:

"Hipertensi niku gerah ingkang berat bu..." (Hipertensi itu adalah sakit yang berat) $(P 1,69$ th, SMP)

\section{Kemudian 3 partisipan lainnya mengatakan bahwa hipertensi adalah penyakit dengan tensi tinggi:

"Gerah hipertensi meniko nggih
pokokipun meniko nggih gerah ingkang
tensine inggil".(sakit hipertensi adalah
sakit dengan tensi tinggi) $(P 4,71$ th,
$S D))(P 2,57$ th, $S D) ;(P 3,61$ th, $S D)$

Ada pula asumsi yang muncul tentang penyakit hipertensi yang diungkapkan oleh partisipan diantaranya yaitu:

Ada 1 partisipan yang menjelaskan bahawa Tensi normal adalah 120/70 $\mathrm{mmHg}$ :

$$
\begin{aligned}
& \text { "...normal niku tensi 120/70.." } \\
& \text { (Normal tensi itu 120/70) (P1, 69 th, } \\
& \text { SMP) ; (P4, } 71 \text { th, SD) }
\end{aligned}
$$


Sedangkan 4 partisipan yang lain mengasumsikan bahwa tensi normal adalah tensi yang dianggap paling enak dirasakan oleh pasien:

"Kulo niku paling normal ning jarang lho mbak niku 140 niku pun paling normal.." (saya itu paling normal tapi jarang lho itu 140 itu sudah paling normal) $(P 2,57$ th, $S D)$

“...normalipun tensi $130 \ldots$... itu pun malah cengeng-cengeng, ning nek 140 atau 150 niku sekeco.." (normal tensi adalah $130 . .$. itupun malah cengeng, tapi kalau 140 atau 150 itu enak) (P3, 61 th, SD); (P4, 71 th, SD); (P6, 65 th, $S D)$

Berdasarkan wawancara juga terdapat 2 partisipan yang mengatakan ketidaktahuannya tentang penyakit hipertensi karena merasa belum di beri informasi:

"Dereng disanjangi nek hipertensi niku nopo" (belum diberi informasi tentang apa itu hipertensi) (P5, $54 \mathrm{th}, S D)(P 7$, 80 th, TS)

\section{Keluhan (Symptom)}

Representasi penyakit hipertensi yang diungkapkan oleh partisipan selanjutnya yaitu terkait keluhan (symptom) dimana hampir seluruh partisipan mengatakan bahwa keluhan yang sering dirasakan adalah pusing disertai dengan tengkuk yang kaku:

“... kepala pusing terus riki cengengcengeng...." (sambil memegang tengkuk) $(P 1,69$ th,$(P 3,61 \mathrm{th}, S D)$;
(P4, 71 th, SD); (P6, 65 th, SD); (P7, 80 th, TS)

Keluhan lain yang disampaikan adalah tidak bisa tidur, tulang-tulang sakit, sering kesemutan, dan ada pula yang kadang mengeluarkan keringat dingin:

“... keluhan itu disini ... terus tidak bisa tidur" (P 1, 69 th, SMP)

\section{“... terus tulang-tulange seluruh badan sakit.. " (P2, 57 th, SD)}

“... gek terus kadang-kadang sok koyo emer-emar ngoten (sambil menunjuk kaki), lalu kadang-kadang seperti kesemutan negitu $(P 2,57$ th, $S D)(P 3$, $61 \mathrm{th}, \mathrm{SD})$

“... cepet capek terus keringat dingin terus kaki dingin " (P5, 54 th, SD)

\section{Penyebab penyakit (Cause)}

Representasi partisipan selanjutnya yaitu terkait penyebab penyakit hipertensi diantaranya adalah karena pikiran, kecapekan, faktor keturunan, serta ada 3 partisipan yang mengungkapkan ketidaktahuan tentang penyebab hipertensi.

"... nopo-nopo dipikir dewe ngaten lho buk dadine nggih ngeten niki" (apaapa dipikir sendiri lho buk jadinya ya kayak gini) (P1, 69 th, SMP)

"... saya tau kalau tensi saya tinggi yo mungkin karena pikiran" (sambil tertawa). (P3, 61 th, SD) ; $(P 4,71$ th, $S D)$ 
"Lha kulo kan dagang dipasar muter, dadose faktor kecapekan" (lha saya kan dagang di pasar muter, jadi ada faktor kecapekan) (P5, 54 th, SD)

"Pokokipun sampun lebih dari 10 tahun mbak amargi nggih kalih keturunan " (pokoknya lebih dari 10 tahun mbak karena ya ada keturunan $)(P 3,61 \mathrm{th}, S D)$

"Sik inggil niku bapak simbok kulo niku nggih inggil" (yang tinggi itu bapak ibu) $(P 5,54$ th, SD)

"Penyebabe mboten ngertos e mbak" (penyebabnya tidak tau mbak)(P2, 57 th, SD) (P6, 65 th, $S D) ;(P 7,80$ th, $T S)$

\section{Lama Penyakit Berlangsung (Timeline)}

Berdasarkan hasil penelitian didapatkan data bahwa lamanya penyakit berlangsung pada partisipan mayoritas adalah 10 tahun atau lebih dengan beberapa riwayat yang berbeda. Ada 2 partisipan yang mengatakan bahwa menderita hipertensi sudah sekitar 10 tahun dan mengetahui hipertensi saat akan dilakukan tindakan operasi

“...... sudah lama ada 10 tahun, ....di rumah sakit Blawong mau dioperasi tapi tidak jadi karena tensinya tinggi".(P 1, 69 th, SMP); (P6, 65 th, SD)

Partisipan ke 3 mengatakan bahwa mengetahui hipertensi sudah lebih dari 10 tahun yang lalu dan diawali dengan gejala stroke

"O.. anu dulu itu pertama itu 280 sampai gejala stroke" (P2, 57 th, SD )
"Pokokipun sampun lebih dari 10 tahun mbak" (Pokoknya sudah lebih dari 10 tahun mbak)(P3, 61 th, $S D)$ (P5, 54 th, SD)

Namun ada 1 partisipan yang baru terdiagnosa hipertensi beberapa bulan ini karena sebelumnya tidak pernah mengikuti kegiatan baik prolanis atau posyandu sebelumnya.

"..Iha nembe 1 tahunan niki kulo ngertos mbak" (Lha baru 1 tahunan ini saya tau mbak) (P7, 80 th, TS)

Partisipan 4 mengetahui hipertensi saat dilakukan pemeriksaan di puskesmas dengan keluhan tertentu dan telah menderita hipertensi selama 8 tahun

"Sampun wonten 8 tahunan niki, nertos pas periksa biasa niku mbak" (sudah ada 8 yahun ini, tahu pas periksa biasa itu mbak) (P4, 71 th, $S D)$

\section{Komplikasi (Consequense)}

Representasi partisipan selanjutnya yaitu terkait komplikasi penyakit hipertensi diantaranya adalah stroke, lumpuh, dan efek obat hipertensi itu sendiri

Representasi penyakit terkait komplikasi, ada beberapa partisipan yang mengatakan bahwa komplikasi penyakit hipertensi akan berakibat terjadi kelumpuhan dan stroke

"Sampun dipun sanjangi menwai tinggi ngendikanipun saged nyebabke stroke dan lumpuh..." (sudah diberitahu bahwa katanya bisa menyebabkan stroke dan lumpuh) $(P 2,57 \mathrm{th}, S D)$; (P3, 61 th, SD); (P6, 65 th, SD) 
"Lumpuh saged, niku pangertosan kulo lho bu." (bisa lumpuh itu sepengetahuan saya bu..) $(P 4,71$ th, $S D)$

Dua Partisipan yang lain mengatakan bahwa komplikasi dari hipertensi yang lain adalah terkait efek obat yang ditimbulkan karena konsumsi jangka lama.

"Jane yo kepiye meneh nek ngombe obat ki kudu rutin ning yo ono efekke..." (sebenarnya yaa ...bagaimana lagi kalau minum obat harus rutin tapi ya efaknya... ) $(P 2,57 \mathrm{th}, S D) ;(P 7,80$ th, $T S)$

\section{Kontrol dan Pengobatan (Control \& Cure)}

Representasi partisipan selanjutnya yang muncul adalah terkait kontrol dan pengobatan dimana semua partisipan berpendapat bahwa hal itu berhubungan dengan konsumsi obat rutin dan kontrol rutin yang telah mereka lakukan per bulan.

"Obate rutin amlodipine dan kaptopril..." (P1, 69 th, SMP) (P2, 57 th, $S D) ;(P 3,61$ th, SD); P4, 71 th, SD); (P5, 54 th, $S D)(P 6,65$ th, $S D) ;(P 7,80$ th, TS $)$

“... kontrol yang rutin itu setiap ada prolanis satu bulan sekali" (P1, 69 th, SM P) (P2, 57 th, SD); (P3, 61 th, SD); P4, 71 th, SD); (P5, 54 th, $S D)(P 6,65$ th, $S D) ;(P 7,80$ th, TS $)$

\section{PEMBAHASAN}

Berdasarkan hasil penelitian penelitian terkait Illness representation pada pasien dengan hipertensi terdapat 6 tema yang muncul yaitu terkait pemahaman penyakit hipertensi, keluhan yang dirasakan, penyebab penyakit, lama penyakit berlangsung, komplikasi yang mungkin muncul, dan kontrol/pengobatan pada penyakit tersebut.

\section{Pemahaman dari penyakit hipertensi}

Berdasarkan hasil wawancara mendalam yang telah dilakukan kepada 7 partisipan ada beberapa data yang didapat terkait pemahaman pasien tentang penyakit hipertensi adalah bahwa hipertensi merupakan suatu sakit yang berat, hipertensi adalah penyakit dengan tensi yang tinggi. Data hasil penelitian ini sesuai dengan teori yang menyatakan bahwa hipertensi adalah tekanan darah persisten dimana tekanan sistoliknya di atas $140 \mathrm{mmHg}$ dan tekanan diastolik di atas $90 \mathrm{mmHg}$ (Smeltzer, S, C \& Bare, B, 2010). Ada pula partisipan lain yang menjelaskan bahwa hipertensi berhubungan dengan tensi normal. Namun di sini ada hal yang menarik karena sebagian besar partisipan mengasumsikan bahwa tensi normal adalah tensi yang dianggap paling enak dirasakan oleh pasien dengan hipertensi. Penderita hipertensi dengan tekanan darah sistolik $140-159 \mathrm{mmHg}$ dan diastolik 90 -99 mmHg perlu melakukan kontrol tekanan darah 3 bulan sekali, sedangkan penderita hipertensi dengan tekanan darah sistolik> $160 \mathrm{mmHg}$ dan diastol > $100 \mathrm{mmHg}$ perlu melakukan kontrol tekanan darah $2-4$ minggu sekali. Hal ini mungkin selaras dengan adanya 
pengaruh sosial budaya yang telah berkembang dikalangan masyarakat tentang persepsi penyakit hipertensi. Karena memang persepsi seseorang ini sangat dipengaruhi oleh social budaya di lingkungannya (Anderson, 2016).

\section{Keluhan yang dirasakan}

Representasi penyakit hipertensi yang diungkapkan oleh partisipan selanjutnya yaitu terkait keluhan (symptom) dimana hampir seluruh partisipan mengatakan bahwa keluhan yang sering dirasakan adalah pusing disertai dengan tengkuk yang kaku. Keluhan lain yang disampaikan adalah tidak bisa tidur, tulang-tulang sakit, sering kesemutan, dan ada pula yang kadang mengeluarkan keringat dingin. Respon partisipan terhadap penyakit hipertensi yang diderita tergambar sebagai respon fisik dan psikologis. Dalam hal ini partisipan dapat mengidentifikasi respon tersebut dan beradaptasi dengan kondisi fisiknya(Oktarina, Haqiqi and Afrianti, 2019).

Hal ini sejalan dengan teori yang menyatakan bahwa hipertensi sering tidak menampakkan gejala sampai bertahun-tahun dan gejala yang tampak biasanya menunjukkan adanya kerusakan vaskuler dengan manifestasi yang khas sesuai sistem organ yang divaskularisasi oleh pembuluh darah yang bersangkutan. Pada pemeriksaan fisik dapat ditemukan keluhan seperti tekanan darah yang tinggi yaitu sistolik di atas $140 \mathrm{mmHg}$ dan diastolic di atas 90 mmHg, sakit kepala, terutama pada daerah oksipital, pusing, palpitasi, mudah lelah, dan perubahan patologis pada ginjal menyebabkan terjadinya nokturia (peningkatan urinasi pada malam hari), serta keluhan yang mengarah ke penyakit vaskuler seperti epistaksis, hematuria, pandangan kabur karena perubahan retina, angina pectoris, dyspnea (Isselbacher, K. J., et al., 2013; Smeltzer, S, C \& Bare, B, 2010)

\section{Penyebab penyakit}

Representasi partisipan selanjutnya yaitu terkait penyebab penyakit hipertensi diantaranya adalah karena pikiran, kecapekan, faktor keturunan, serta ada 3 partisipan yang mengungkapkan ketidaktahuan tentang penyebab hipertensi. Berdasarkan hasil penelitian yang lain terdapat 5 faktor yang dapat menimbulkan kejadian hipertensi dengan penyebab hipertensi yaitu riwayat keluarga, kebiasaan merokok, aktivitas/olahraga, pola asupan garam, dan stress(Raihan and Dewi, 2014)

\section{Lama penyakit berlangsung}

Berdasarkan hasil penelitian didapatkan data bahwa lamanya penyakit berlangsung pada partisipan mayoritas adalah 10 tahun atau lebih dengan beberapa riwayat yang berbeda. Ada yang mengatakan bahwa mengetahui hipertensi saat akan dilakukan tindakan operasi, ada yang diawali dengan gejala stroke. Namun ada pula partisipan 
yang baru terdiagnosa hipertensi beberapa bulan karena sebelumnya tidak pernah mengikuti kegiatan baik prolanis atau posyandu lansia. Penelitian lain menyebutkan bahwa pasien dengan hipertensi memiliki pengalaman pertama dengan hipertensi yang tidak control. Hal tersebut terjadi karena banyak dari pasien tidak merasakan secara langsung gejala yang mengganggu aktivitasnya (Oktarina, Haqiqi and Afrianti, 2019).

\section{Komplikasi yang mungkin muncul}

Representasi partisipan selanjutnya yaitu terkait komplikasi penyakit hipertensi, dimana mereka mengatakan bahwa penyakit hipertensi dapat mengakibatkan stroke dan kelumpuhan, serta efek obat hipertensi yang tidak baik karena obat yang harus dikonsumsi jangka lama. Hipertensi dapat membahayakan penderita karena saat tertentu bisa menyebabkan komplikasi pada jantung, mata, otak, penbuluh darah, ginjal maupun organ vital lainnya (Primanita, 2011).

\section{Kontrol/pengobatan pada penyakit}

Representasi partisipan selanjutnya yang muncul adalah terkait kontrol dan pengobatan dimana semua partisipan berpendapat bahwa hal itu berhubungan dengan konsumsi obat rutin dan kontrol rutin yang telah mereka lakukan per bulan melalui even prolanis di puskesmas. National Heart, Lung and Blood Institute menyatakan dalam artikelnya bahwa penderita darah tinggi harus terus menerus mendapatkan perawatan medis dan mengikuti anjuran dari pertugas kesehatan. Perawatan darah tinggi memang harus tetap dilakukan meskipun kondisi pasien sedang sehat, sehingga tekanan darah tetap bisa di control (Lauer et al., 2015)

\section{KESIMPULAN}

Berdasarkan analisa terhadap 7 partisipan maka dapat disimpulkan bahwa gambaran Illness Represetations yang muncul pada pasien dengan hipertensi adalah menyangkut tentang pemahaman penyakit hipertensi; keluhan yang dirasakan pasien; penyebab penyakit; lama penyakit berlangsung; komplikasi yang mungkin muncul; dan kontrol atau pengobatan

\section{DAFTAR PUSTAKA}

Anderson, R. D. (2016) '2014 ACC / AHA Guidelines for the Management of Patients with Valvular Heart Disease Disclosures Biosense Webster ( a J \& J Co .) consultant'.

Creswell John W (2014) Penelitian Kualitatif \& Desain Riset. Yogayakarta: Pustaka Pelajar.

Fitri, R. A. and Fensi, F. (2008) 'Representasi Penyakit Dan Strategi Pengatasan Pada Anak Yang Menderita Kanker', Jurnal Ilmiah Psikologi, 2(1), pp. 8-13. Available at:https://media.neliti.com/media/publi 
cations/99509-ID-representasi-

penyakit-dan-strategi-penga.pdf.

Hamzah, I. F., Dewi, E. K. and Suparno, S. (2014) 'Makna Sakit Pada Penderita Penyakit Jantung Koroner: Studi Fenomenologis', Jurnal Psikologi Undip, 13(1), pp. 1-10. doi: 10.14710/jpu.13.1.1-10.

Isselbacher, K. J., Braunwald, E., Wilson, J. D., Martin, J. B., Fauci, A. S., \& Kasper, D. L. (2013) Prinsip-Prinsip Ilmu Penyakit Dalam. Jakarta: EGC.

Kementrian Kesehatan RI (2013) Riset Kesehatan Dasar 2013, Badan Penelitian dan Pengembangan Kesehatan. Available at: http://www.riskesdas.litbang.depkes.g o.id/download/TabelRiskesdas2010.pd f.

Lauer, M. S. et al. (2015) 'National Heart, Lung, and Blood Institute (NHLBI) strategic visioning setting an agenda together for the NHLBI of 2025', Circulation, 131(12), pp. 1106-1109. doi:

10.1161/CIRCULATIONAHA.115.01 5712.

Nursalam (2015)

METODOLOGI

PENELITIAN ILMU

KEPERAWATAN. 4th edn. Edited by

P. P. Lestari. Jakarta. Available at:http://ners.unair.ac.id/materikuliah/3 -2Metodologi_Nursalam_EDISI 4-21
NOV.pdf.

Oktarina, E., Haqiqi, H. and Afrianti, E. (2019) 'Studi Fenomenologi Tentang Pengalaman Pasien Hipertensi Terhadap Perawatan Dirinya di Wilayah Kerja Puskesmas Andalas Padang Tahun 2017', NERS Jurnal Keperawatan, 14(1), p. 1. doi: 10.25077/njk.14.1.1-10.2018.

Primanita, A. (2011) HUBUNGAN ANTARA PERSEPSI TENTANG SAKIT DENGAN PEMANFAATAN PELAYANAN KESEHATAN OLEH PESERTA JAMINAN KESEHATAN MASYARAKAT DI PUSKESMAS GUNUNGPATI KOTA SEMARANG. SEMARANG. Available at: https://lib.unnes.ac.id/5819/1/7564.pdf

Raihan, L. N. and Dewi, A. P. (2014) 'Hipertensi Primer Pada Masyarakat Di Wilayah Kerja', pp. 1-10.

Sandelowski, M. (2000) 'Focus on research methods: Whatever happened to qualitative description?', Research in Nursing and Health, 23(4), pp. 334340. doi:10.1002/1098-

Smeltzer, S, C \& Bare, B, G. (2010) 'Buku Ajar Keperawatan Medikal Bedah Brunner \& Suddarth Edisi 8 Vol 3'.

WHO (2011) Hypertension fact sheet, Hypertension.

Yonata, A., Satria, A. and Pratama, P. 
(2016) 'Hipertensi sebagai Faktor

Pencetus Terjadinya Stroke', Majority, 5(3), p. 17. 